\title{
GLOBAL INNOVATIVE ECONOMICS AND DEVELOPMENT ASPECTS OF IMERETI - REGION
}

\section{TSITSINO DZOTSENIDZE}

\author{
Academic Doctor of Economics, \\ Associated Professor \\ Kutaisi University, Georgia \\ tsitsino.dzotsenidze@unik.edu.ge
}

Abstract. Technological progress and innovation go hand in hand with the history of human civilization. It has a profound effect on the development of modern life. EU institutions, along with national institutions of member and associate countries, as well as a growing number of international and global political institutions, are major sources of 21st century formation. EU policy affects not only the lives of more than 500 million Europeans, but also global trends in areas such as climate change, resource utilization and sustainability, trade, healthcare, regional conflict resolution and poverty reduction. The aim of the paper is to show the trends of technological innovations that will play a big role in our lives in both the short and long term.

\section{KEYWORDS: GLOBAL INNOVATIVE ECONOMICS, IMERETI-REGION.}

For citation: Dzotsenidze, Ts., (2020). Global Innovative Economics and Development Aspects of Imereti Region. Globalization and Business, 10. 261-263. https://doi.org/10.35945/gb.2020.10.035

Technological progress and innovation go hand in hand with the history of human civilization. It has a profound effect on the development of modern life. In his time inventing the bow was a revolution in the hunting process, as was the invention of the wheel in the shipment of cargo. The invention of railroads, automobiles, and airplanes revolutionized transportation; And the telephone, mobile communications, and the Internet have made it so easy to talk to each other as if we were all living in one big global village on earth.

Although all of these technologies have been of great benefit to mankind, they have sometimes had unintended negative consequences. They often violated the existing public order, leading to unrest and damage. The human community must be taught to use innovation properly.

Technological development is continuing. It is becoming more and more important for the public and politicians to anticipate the possible news that will change the rules of the game and will be able to bring both benefits and harms. The task of the state is to develop agreed-upon measures to maximize benefits and minimize losses. (Klein, Maury, 2018):

In advance State measures may take different forms, such as: legislation regulating technology (some types of restrictions may apply here); Public actions that will promote the development and implementation of technologies through norms and regulations; Educational and propaganda activities for the benefit of the public; Compensatory measures for those sections of society who may suffer as a result of the introduction of new technologies. (Perez, Carlota, 2019).
EU institutions, along with national institutions of member and associate countries, as well as a growing number of international and global political institutions, are major sources of 21st century formation. EU policy affects not only the lives of more than 500 million Europeans, but also global trends in areas such as climate change, resource utilization and sustainability, trade, healthcare, regional conflict resolution and poverty reduction.

The role of the European Parliament in developing regional and global strategies is big. This finds its expression at many different levels: in hearings organized by individual members, in discussions organized by political groups and committees.

The European Commission for the Evaluation of Science and Technology Options (STOA) has a major role to play. STOA supports the work of parliamentary committees in developing long-term policies. At their request, it conducts promising research, and actively takes the initiative to identify works of technological development that leave a deep mark on the life of society. All this justifies their inclusion in the global political agenda.

The aim of the paper is to show the trends of technological innovations that will play a big role in our lives in both the short and long term.

Electric cars. We are on the verge of switching to electric cars, and the question is: what will be the consequences of this transition to climate, our health, and our lifestyle in the future?

Over the last century, cars have become an integral part of human life. They offer more flexibility and speed 
than alternative transport types and are available to a large portion of people. From the beginning of mass production, cars were used mainly for internal combustion engines. (ICE) They used fossil fuels such as gasoline and diesel. Through them, energy was generated that returned the wheels and performed other auxiliary actions. In addition, automobiles are the main source of $\mathrm{CO} 2$ (carbon dioxide) nitrogen oxide (NOx) emissions into the atmosphere, affecting global warming and polluting the air, especially in urban areas. It is these problems that have led to the urgency of the use of electricity in cars.

Economic policy and development. Electric cars have a number of advantages. In order to reduce air pollution and reduce $\mathrm{CO} 2$ emissions, electric vehicles offer a number of additional advantages. They need to spend much less on maintenance; Are quiet and easy to manage, reduce our dependence on imported energy. They can have a positive effect on the balance of payments internationally, and they can even contribute to the settlement of international conflicts when this conflict is related to natural resources.

Unfortunately, the production of electric cars is still much more expensive than that of cars with an internal combustion engine. Meanwhile, electric cars have a limited operating range. Nowadays, it can travel $300 \mathrm{~km}$ between recharges, and in the end, it takes much longer to charge than it does to refuel. (Šmihula, Daniel, 2011: 50-69).

Against the backdrop of these challenges, several EU member states have used subsidies to help create an electric car market that will help increase production and sales volumes, and ultimately reduce costs. At the same time, intensive efforts are being made to develop battery technologies to produce cheaper and lighter batteries.

While one day we might create electric cars that fit the relatively low price and a large assortment of modern ICE cars, such a scenario may not be necessary or desirable. The car of the future is very different from the cars we are creating now.

Today, many people still own a personal car, usually one. Everyone is trying to own a multifunctional car, which will be enough space for all the family members and where there will be enough space at the same time, for example, to carry furniture. It must have air conditioning and heating devices, a large fuel tank and conduction systems in the cities. As a result, modern «multifunctional» cars are very massive, heavy, and thus inefficient. This problem is exacerbated by electric cars, where batteries often increase car weight by $33 \%$. Ironically, this means that much of the energy stored in batteries is simply needed to carry a heavier battery.

Ironically, much of the energy stored in the batteries must be used to move more and more of the heavier battery block.

Despite this, the younger generation is increasingly moving away from the traditional system of owning a personal car. Instead, the practice of owning a car on a shared basis is gaining ground. In addition, because sharing companies offer their customers a choice of different vehicles, a separate car no longer needs to be as functional as it used to be in the case of private cars.
Instead, they may be more versatile, lighter, and also offer customers shorter mileage, which will require a lighter battery, which will ultimately increase the efficiency of this car.

Depending on how city dwellers choose to use cars together, private ownership of cars will shift to suburban residents who live in private homes and generate their own electricity. Such PV in photovoltaic includes a system of batteries that collect energy during the day and use it later in the evening. Existence of battery systems for such families, both at home and in the car, may be exaggerated. Instead, maximum efficiency will mean a minimum number of batteries, which will be permanently installed on the car so that it provides a daily requirement for fuel. The rest of the batteries in the homes will be connected to the PV system and will be used in cars for holidays, vacations and weekends.

The price of electricity has a big impact on the attractiveness of electric cars. According to the worst case scenario, if thousands of electric cars are loaded at once, it will inevitably cause the electrical network to overload, making it unstable and requiring additional investment. On the other hand, if the cars were to be loaded at the specified time, the electricity costs would be reduced and the electricity would become more stable. (Philip S. Anton, Richard Silberglitt, James Schneider, 2011).

Preparatory policy. There is a broad consensus that the successful introduction of e-mobility will depend on public action, encouragement and support programs. All attention should be paid to making car owners interested in electric vehicles on the one hand and creating a charging infrastructure on the other hand, creating a proper infrastructure that will allow customers to use electric cars as well as vehicles with internal combustion engines.

In our view, it would be better for the state to focus on the production of new electric vehicles, instead of focusing on the production and promotion of new electric vehicles, which would be more and more able to engage and adapt in the process of sharing cars. Facilitating the development of light vehicles for car sharing services is more appropriate than subsidizing heavy electric vehicles for private consumers who want to emulate the efficiency of their current vehicles. We also need to focus on how to integrate with e-mobility over the next 20 years, when even more private homes will be equipped with PV and batteries with energy storage systems.

The geopolitical location of the Imereti region is an important resource potential, which is reflected in the role of the transit corridor connecting Europe and Asia. Distance from the administrative center of the region - from Kutaisi to the nearest seaport - $102 \mathrm{~km}$, to the capital - $236 \mathrm{~km}$. There are 2 airports in Kutaisi, one of which has international flights. Consequently, transport and communication are one of the major sectors of the regions economy.

688 active enterprises operate in the transport and communication sector in Imereti, the largest share of the transport and communication sector occupies $84.7 \%$ (583 enterprises).

Kutaisi is connected to almost all regional centers of Georgia by bus / micro bus. However, a large part of the car fleet is outdated, failing to meet modern requirements, and 
the quality of their service is justifiably dissatisfied with both locals and foreign tourists.

Experts believe that the lack of a state regulation system in the field is one of the main reasons for the low quality of service and safety in long-distance passenger transport. Long-distance passenger transportation in the country is not subject to special licensing or issuance of licenses, therefore the activities of transport companies or individuals cannot be controlled.

Another area of passenger transport is domestic urban transport, which usually exists in large cities, and in most cases it is owned by the municipality or subsidized by the municipal budget. Kutaisi is the only major city in the country (unlike Tbilisi, Batumi and Rustavi) in which public transport is fully privately owned and the local municipality is limited to issuing permits only to carriers. As a result, although the fare is lower than in all other municipalities, the quality of service is adequate and causes dissatisfaction and annoyance to passengers, both local and foreign tourists.

Renovation of the existing obsolete transport park will require about 20-25 million for the first phase. GEL investment, which is also added to the costs of arranging other ancillary infrastructure (passenger waiting rooms, billboards, etc.). However, the implementation of this investment will not be economically justified in the case of existing tariffs. Therefore, in order to renew the city transport and improve the quality of service, it is necessary to increase the tariffs and / or subsidize the tariffs, as the case is in other cities of Georgia.

Imereti region is the geographical center of Georgia, the main roads of the country pass through it, the improvement of which will further increase the regions transit potential in the future, but experts believe that the region should have not only a simple carrier, but also a modern logistics center.

The project "Shared Car» has been launched in the capital, which includes the service of using an electric car. In 2020, the first electric car will be created under the Georgian brand. The holding company, which unites companies such as aienergy, aicar, aipower and aiproduction, starts operating in the Georgian market. Holding is the first industrial business group not only in Georgia, but also in the Caucasus, which is beginning to invest in complex environmental projects.

It should be noted that the holding includes the service of installation of "Carsharing", electric chargers and solar panels, and one of the main directions of the company is to start the production of electric cars in Georgia.

"Carsharinging» service is already available. The news has been launched for two months and at this stage the company has 50 electric cars in Tbilisi. "Shared car service has already been launched and citizens can use it. Anyone can download the application and use the service without any problems. We currently have 50 electric cars. We are waiting for the arrival of new cars and in the first stage, there will be 300 cars, and in total we have decided to import about 3,000 electric cars," said Giorgi Khurodze.

If we want our cities to be able to live in the future, renewing public transport is inevitable. Ultimately, a public action that will help promote e-mobility will be justified if it is closely coordinated with the development of new methods of mobility and new ways of generating and disseminating electricity.

\section{REFERENCES}

Klein, Maury (2018): The Technological Revolution, in The Newsletter of Foreign Policy Research Institute, 13(18);

Perez, C. (2019): Technological revolutions and techno-economic paradigms., in Working Papers in Technology Governance and Economic Dynamics, Working Paper 20, (Norway and Tallinn University of Technology, Tallinn);

Šmihula, D. (2011): Long waves of technological innovations, Studia politica Slovaca, 2/2011, Bratislava, ISSN 1337-8163, 5069;

Drucker, P. F. (1965): The First Technological Revolution and Its Lessons;

Philip S. Anton, Silberglitt, R., \& Schneider, J. (2011): The Global Technology Revolution - Bio/Nano/Materials Trends and Their Synergies with Information Technology by 2015., RAND, ISBN;

Bedianashvili, G. (2019). Knowledge economic, enterpreneurial activity and cultur factor in modern conditions of Gobalization: chelenges for Georgia. Globalization and Business, 5. https://www.eugb.ge/view_archive.php?cat=5\#;

Papava V., (2017). Politization of the economy and non-ecobomic policy (experience of post communist Georgia).

Chikhladze, N., Rusadze, N., (2015). The role of budget investments in the socio-economic development of the region. International Economic Conference IEC 2015. Models of National Economic Development: Yesterday, Today, Tomorrow, Proceedings. Business Engineering. https://drive.google.com/file/d/0B3PZSQNPT43SWUtLSUszbkh6VFE/ view?pref=2\&pli=1 152-156;

Gechbaia, B., \& Qoqiauri, L., (2019). Main blocks and models of the national innovative system. Scientific bulletin of Polissia, 1 (17), 2019. 41-54. DOI: 10.25140/2410-9576-2019-1(17)-41-54;

Gechbaia, B., \& Mamuladze, C., 2016 Priorities of the innovative economy in the EU and the current problems of its formation. Innovative Economics and Management. 2, 9-12. 